\title{
Stress Induced Phosphate Solubilization by Aspergillus awamori bxq33110 Isolated from Waste Mushroom Bed of Agaricus bisporus
}

\author{
Buddhi Charana Walpola, June-Seob Song, Kab-Yeul Jang ${ }^{1}$, and Min-Ho Yoon* \\ Department of Bio-Environmental Chemistry, College of Agriculture and Life Sciences, \\ Chungnam National University, Daejeon, 305-764, Korea \\ ${ }^{1}$ Mushroom Research Division, National Institute of Horticultural \& Herbal Science, RDA, Suwon 441-706, Korea

\begin{abstract}
A fungal strain, capable of solubilizing insoluble phosphate under diverse temperature, $\mathrm{pH}$ and salt conditions was isolated from Waste Mushroom bed of Agaricus bisporus in South Korea. Based on 18S rRNA analysis, the strain was identified as Aspergillus awamori bxq33110. The strain showed maximum phosphate solubilization in AYG medium $\left(525 \mu \mathrm{g} \mathrm{mL}^{-1}\right)$ followed by NBRIP medium $\left(515 \mu \mathrm{g} \mathrm{mL}^{-1}\right)$. The strain solubilized $\mathrm{Ca}_{3}\left(\mathrm{PO}_{4}\right)_{2}$ to a greater extent and rock phosphate and $\mathrm{FePO}_{4}$ to a certain extent. However $\mathrm{AlPO}_{4}$ solubilizing ability of the strain was found to be very low. Glucose at the rate of $2 \%\left(561 \mu \mathrm{g} \mathrm{mL}^{-1}\right)$ was found be the best carbon source for Aspergillus awamori bxq33110 to solubilize maximum amount of phosphate. However, no significant difference $(P \leq 0.05)$ in phosphorus solubilization was found between $1 \%$ and $2 \%$ glucose concentrations. $\left(\mathrm{NH}_{4}\right)_{2} \mathrm{SO}_{4}$ was the best nitrogen source for Aspergillus awamori bxq33110 followed by $\mathrm{NH}_{4} \mathrm{Cl}$ and $\mathrm{NH}_{4} \mathrm{NO}_{3}$. At pH 7 , temperature $30{ }^{\circ} \mathrm{C}$ and $5 \%$ salt concentration $\left(674 \mu \mathrm{g} \mathrm{mL}^{-1}\right)$ were found to be the optimal conditions for insoluble phosphate solubilization. However, strain Aspergillus awamori bxq33110 was shown to have the ability to solublize phosphate under different stress conditions at $30-40{ }^{\circ} \mathrm{C}$ temperature, pH 7-10 and $0-10 \%$ salt concentrations indicating it's potential to be used as bio-inoculants in different environmental conditions.
\end{abstract}

Key words: Phosphate solubilization, Aspergillus awamori bxq33110, Bio-inoculants

\section{Introduction}

Phosphorus is the second most important macro-nutrient required by the plants and it is the key nutrient for sustainable agricultural production. Soluble inorganic phosphate applied to soil as chemical fertilizer, is rapidly immobilized and become unavailable to plants (Mundra et al., 2011). This leads to an excess application of phosphorus fertilizer to crop plants (Goldstein, 1986), and the continued and unabated use of these fertilizers have negative impacts on the environment.

Some microorganisms are known to be effectively involved in the transformation of insoluble phosphate to soluble forms that can be taken up by plants. This is achieved through various processes such as acidification, chelation, ion exchange reactions and production of low molecular weight different organic acids (Chaiharn and

\footnotetext{
Received : 2012. 4. 27 Accepted : 2012. 5. 29

*Corresponding author : Phone: +82428216733

E-mail: mhyoon@cnu.ac.kr
}

Lumyong, 2009). Therefore, the potential use of phosphate solubilizing microorganisms to increase crop production through its application as bio-inoculants has attracted the attention of researchers. Soil inoculation with phosphate solubilizing microorganisms (PSMs) has been shown to improve solubilization of fixed soil phosphates and release soluble phosphorous resulting in higher crop yields.

The use of green houses for cultivation has dramatically increased in South Korea during last three decades (Lee and Kim, 2006). Repeated cultivation and application of chemical fertilizer cause soil degradation due to high salt and insoluble phosphate accumulation. This has become a great matter of concern in these areas. PSMs are found in the majority of the soils, but the activity is severely influenced by environmental factors especially under stress conditions. Therefore, PSMs with the genetic potential for increasing tolerance to high temperature, $\mathrm{pH}$ and salt concentration may be important factor in the establishment, multiplication and producing environmentally 
friendly bio-inoculants. Therefore, the objective of this study was to isolate and characterize PSM which solubilizes phosphates at high salt, high $\mathrm{pH}$ and high temperature conditions.

\section{Materials and Methods}

Isolation of strain Fungal strain was isolated from waste mushroom bed of Agaricus bisporus collected from Chungchugnam-do province, Buyeo-Gun area in South Korea. Serial dilution of soil solution were spread on NBRIP (National Botanical Research Institute Phosphorus) agar plates containing $10 \mathrm{~g}$ glucose, $5 \mathrm{~g} \mathrm{Ca}_{3}\left(\mathrm{PO}_{4}\right)_{2}, 5 \mathrm{~g}$ $\mathrm{MgCl}_{2} \cdot 6 \mathrm{H}_{2} \mathrm{O}, 0.25 \mathrm{~g} \mathrm{MgSO}_{4} \cdot 7 \mathrm{H}_{2} \mathrm{O}, 0.2 \mathrm{~g} \mathrm{KCl}, 0.1 \mathrm{~g}$ $\left(\mathrm{NH}_{4}\right)_{2} \mathrm{SO}_{4}$ in $1 \mathrm{~L}$ distilled water (Nautiyal, 1999). The plates were incubated for 5 days at $30^{\circ} \mathrm{C}$. Formation of clear halo zone around the colonies after 5 days of incubation indicates phosphate solubilizing ability. It was further purified by re-culturing on the fresh NBRIP agar plates. The fungal strain that exhibited large clear zone on the agar plates was selected as phosphorus solubilizing organisms for further studies (Fig. 1).

18S IRNA gene sequencing and Phylogenetic analysis of the isolated strain The partial sequencing of 18S rRNA of the strain was done with the help of the DNA sequencing service (SOLGENT, Daejeon-si, South Korea). The online program BLAST was used to find out the related sequences with known taxonomic information available at the databank of NCBI (http://www.ncbi.nlm. nih.gov/BLAST). A Phylogenetic tree (Fig. 2) was constructed using CLUSTAL X program, which involved

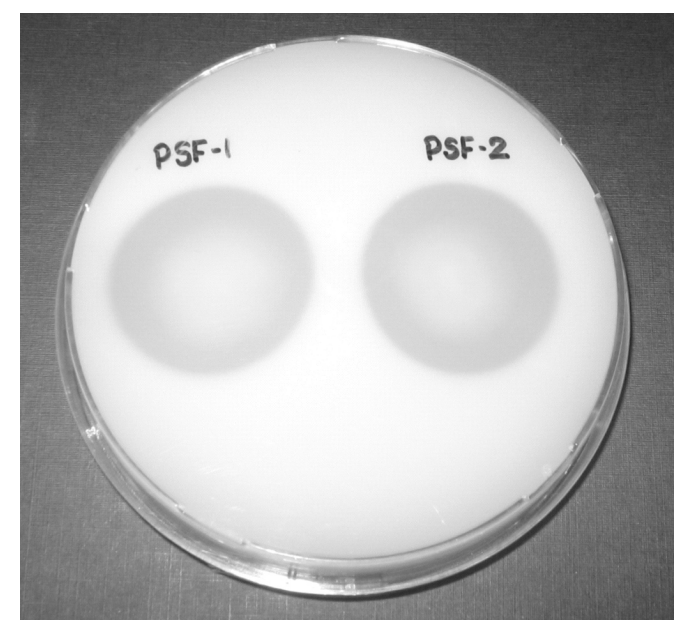

Fig. 1. Halo zone produced by Aspergillus awamori bxq33110 on agar plates due to Phosphorus solubilization. sequence alignment by neighbor joining method and maximum parsimony using the MEGA4 program. Grouping of sequences was based on confidence values obtained by bootstrap analysis of 1,000 replicates. Gaps were edited in the BioEdit program and the evolutionary distances were calculated using the Kimura two parameter model.

\section{Assay of phosphorus solubilizing abilities Phos-} phorus solubilization ability of fungal strain was assayed using different types of liquid media (Table 1) as described by Srividya et al. (2009). All the other experiments were conducted in NBRIP liquid media. Sterilized $500 \mathrm{~mL}$ Erlenmeyer flasks $(n=3)$ containing $200 \mathrm{~mL}$ NBRIP liquid medium were inoculated by transferring 10 $\mathrm{mm}$ diameter mycelia disc from a fully sporulating culture and incubated for 7 days with continuous shaking at $30^{\circ} \mathrm{C}$. Sterilized uninoculated medium served as a control. A $10 \mathrm{~mL}$ sample of each cultured and control were taken into centrifugation tube and centrifuged in each day for $15 \mathrm{~min}$ at $8,000 \mathrm{rpm}$. The clear supernatant was used as determine phosphorous release into the medium using the phospho-molybdate blue color method (Murphy and Riley, 1962). The $\mathrm{pH}$ of the culture medium was also recorded with the $\mathrm{pH}$ meter equipped with glass electrode.

The $\mathrm{Ca}_{3}\left(\mathrm{PO}_{4}\right)_{2}$ solubilization assay performed as described above and $\mathrm{AlPO}_{4}$ and $\mathrm{FePO}_{4}$ solubilization was assayed by adding $4 \mathrm{~g} \mathrm{~L}^{-1} \mathrm{AlPO}_{4}$ or $6 \mathrm{~g} \mathrm{~L}^{-1} \mathrm{FePO}_{4} \cdot 2 \mathrm{H}_{2} \mathrm{O}$ instead of $\mathrm{Ca}_{3}\left(\mathrm{PO}_{4}\right)_{2}$ in NBRIP medium. Rock phosphate solubilization ability was assayed using rock phosphate having $\mathrm{P}_{2} \mathrm{O}_{5}$ content $28 \%$ instead of $\mathrm{Ca}_{3}\left(\mathrm{PO}_{4}\right)_{2}$ in NBRIP medium. These amounts are equal to phosphorus as in the standard NBRIP medium.

Phosphate solubilizing ability of fungal strain was tested under different carbon and nitrogen sources. The

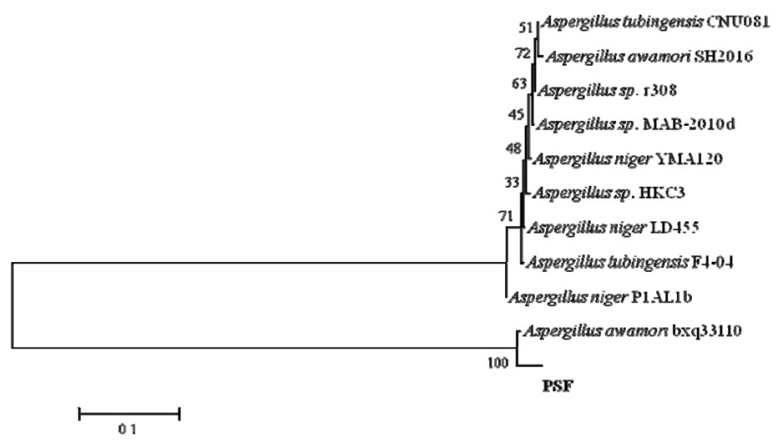

Fig 2. Phylogenetic tree showing the relationship between isolated phosphate solubilizing fungi (PSF) and representatives of other related taxa. 
Table 1. Composition of different media used for assay phosphate solubilization.

\begin{tabular}{|c|c|c|c|c|c|c|}
\hline Components & $\mathrm{M} 1^{\dagger}$ & M2 & M3 & M4 & M5 & M6 \\
\hline \multicolumn{7}{|c|}{ 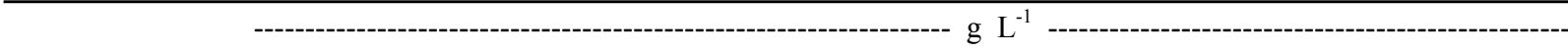 } \\
\hline Glucose & 10 & 20 & 10 & 100 & 10 & 10 \\
\hline$\left(\mathrm{NH}_{4}\right)_{2} \mathrm{SO}_{4}$ & 0.5 & 1 & - & - & 0.5 & 0.1 \\
\hline $\mathrm{MgSO}_{4} \cdot 7 \mathrm{H}_{2} \mathrm{O}$ & 0.1 & 0.5 & 0.4 & 0.2 & 0.1 & 0.25 \\
\hline Yeast extract & 0.5 & 0.2 & 0.5 & - & - & - \\
\hline $\mathrm{KCl}$ & 0.2 & - & - & - & 0.2 & 0.2 \\
\hline $\mathrm{NaCl}$ & 0.2 & - & 1 & - & 0.2 & - \\
\hline $\mathrm{FeCl}_{3}$ & - & Trace & - & - & - & - \\
\hline $\mathrm{FeSO}_{4} \cdot 7 \mathrm{H}_{2} \mathrm{O}$ & 0.002 & - & - & - & 0.002 & - \\
\hline $\mathrm{MnSO}_{4} \cdot \mathrm{H}_{2} \mathrm{O}$ & 0.002 & Trace & - & - & 0.002 & - \\
\hline $\mathrm{MgCl}_{2} \cdot 6 \mathrm{H}_{2} \mathrm{O}$ & - & - & - & - & - & 5 \\
\hline $\mathrm{CaCl}_{2}$ & - & - & 0.2 & - & - & - \\
\hline $\mathrm{NH}_{4} \mathrm{NO}_{3}$ & - & - & 1.5 & 0.5 & - & - \\
\hline $\mathrm{ZnSO}_{4}$ & - & - & - & 0.004 & - & - \\
\hline $\mathrm{Ca}_{3}\left(\mathrm{PO}_{4}\right)_{5}$ & 5 & 5 & 5 & 5 & 5 & 5 \\
\hline $\mathrm{pH}$ & 7 & 6.8 & 7 & 5 & 7 & 7 \\
\hline
\end{tabular}

${ }^{\mp}$ M1, (PVK; Pikovskaya, 1948); M2, (AYG; Halder et al., 1991); M3, (Kim et al., 1997); M4, (Vassilev et al., 1998); M5, (NBRIY; Nautiyal, 1999); M6, (NBRIP; Nautiyal, 1999).

effect of carbon source on phosphate solubilization was tested by adding sucrose, mannitol and lactose instead of glucose in the NBRIP medium. To test the effect of the nitrogen source, $\left(\mathrm{NH}_{4}\right)_{2} \mathrm{SO}_{4}$ in the NBRIP medium was replaced by $\mathrm{NH}_{4} \mathrm{NO}_{3}, \mathrm{KNO}_{3}, \mathrm{NaNO}_{3}$ and $\mathrm{NH}_{4} \mathrm{Cl}$.

Estimation of stress induced phosphate solubilizing capacity Stress tolerance phosphate solubilizing capacity of strain was assayed using a high $\mathrm{pH}$, high temperature and high salt concentration medium. The effect of salt on phosphate solubilization was tested by growing the strain on NBRIP containing various amounts of $\mathrm{NaCl}(0 \%$, $2.5 \%, 5 \%$ and $10 \%$ ) concentrations. Further, to check the effect of $\mathrm{pH}$ on phosphate solubilization was tested by adjusting the $\mathrm{pH}$ of NBRIP medium using $\mathrm{HCl}$ or $\mathrm{NaOH}$ to different $\mathrm{pH}$ levels (7-10). For estimation of high temperature induced phosphate solubilization NBRIP medium inoculated strain was incubated at different temperature conditions $\left(30-60^{\circ} \mathrm{C}\right)$. In all cases, phosphate solubilization and $\mathrm{pH}$ of the culture medium were measured described earlier.

\section{Results and Discussion}

Isolation and Identification of insoluble phosphate solubilizing fungal strain A fungal strain, which was named Aspergillus awamori bxq33110, had a marked insoluble phosphate solubilizing ability as visualized by the clear zone developed around the mycelium after 5 day incubation at $30^{\circ} \mathrm{C}$ (Fig. 1). It was seen that halo zone increased with increase in colony diameter. Solubilization Index (colony diameter + halo zone diameter/ colony diameter) was found to be reached to the peak at 2 days after inoculation (2.67) followed by gradual reduction

Assay of phosphorus solubilizing abilities For the assay of phosphate solubilization ability in liquid medium, researchers have used different medium with different composition. As depicted in Fig. 3, phosphate solubilization was varied according to the medium. Medium 2 (AYG; Halder et al., 1991) and medium 6 (NBRIP; Nautiyal, 1999) showed the maximum phosphate solubilization (525 and $515 \mu \mathrm{g} \mathrm{mL}^{-1}$ filtrate, respectively) with the $\mathrm{pH}$ drop from 6.80 to 3.86 and from 7.00 to 3.95 respectively after 2 days incubation. However, there was no significant difference $(\mathrm{P} \leq 0.05)$ in phosphorus solubilization between AYG and NBRIP medium. Considering amount of glucose and other chemical composition in the medium, NBRIP proved to be most cost effective without much compromising the phosphate solubilization. Therefore all other studies were done using NBRIP as medium. Phosphate solubilization ability $\left(52 \mu \mathrm{g} \mathrm{mL}^{-1}\right.$ 


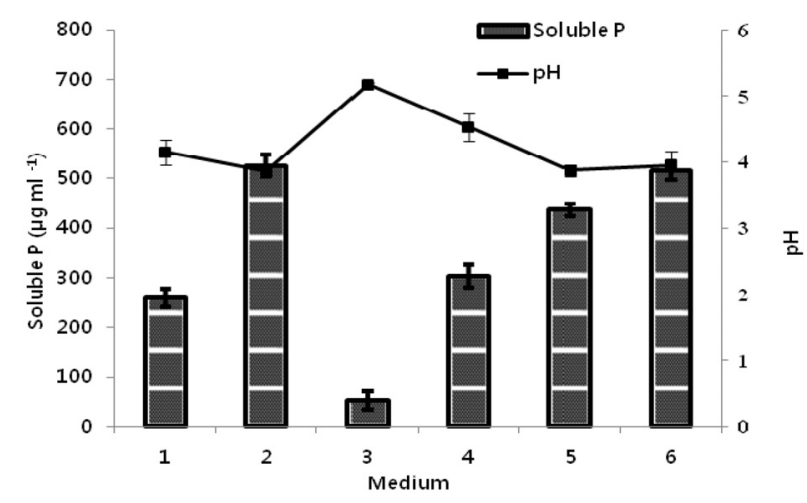

Fig. 3. Effect of different media on insoluble phosphate solubilization by Aspergillus awamori bxq33110. Values are mean \pm SD of three replicates.

M1 (PVK; Pikovskaya, 1948), M2 (AYG; Halder et al., 1991), M3 (Kim et al., 1997), M4 (Vassilev et al., 1998), M5 (NBRIY; Nautiyal, 1999), M6 (NBRIP; Nautiyal, 1999).

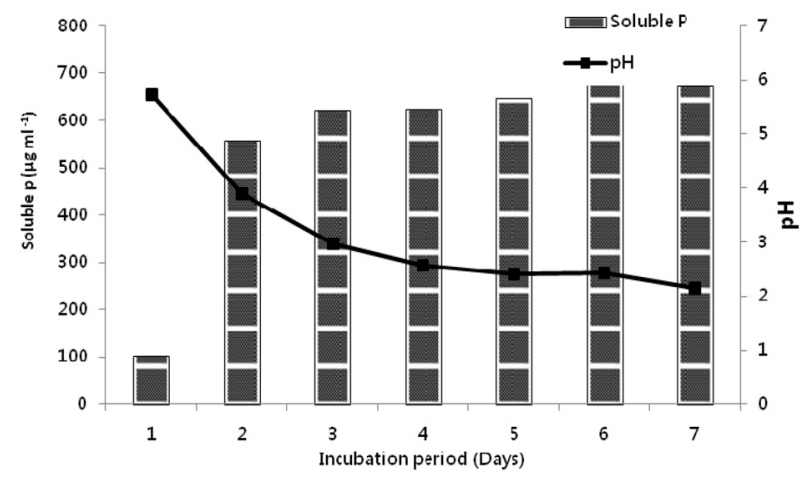

Fig. 4. Insoluble phosphate solubilization by Aspergillus awamori bxq33110 in NBRIP medium. Values are mean \pm SD of three replicates.

filtrate) and $\mathrm{pH}$ reduction (from 7.00 to 5.17) was very low with medium M3 in Table 1 (Kim et al., 1997).

After confirming the medium, insoluble phosphate solubilizing ability of Aspergillus awamori bxq33110 was assayed in NBRIP liquid medium and soluble phosphorus content and $\mathrm{pH}$ were measured daily up to one week (Fig. 4). The level of soluble phosphorus in the culture filtrate increased significantly $\left(674 \mu \mathrm{g} \mathrm{mL}^{-1}\right)$ and remained high for several days. However subsequently a significant drop in soluble phosphorus level was observed on later days when incubation period progressed. There was no significant change in the content of soluble phosphorus under the control, which only resulted in a negligible slightly increase throughout the incubation period. Fungal strain lowered the $\mathrm{pH}$ of the NBRIP medium as compared with the control where it remained constant. This was seen as rapid decrease during the

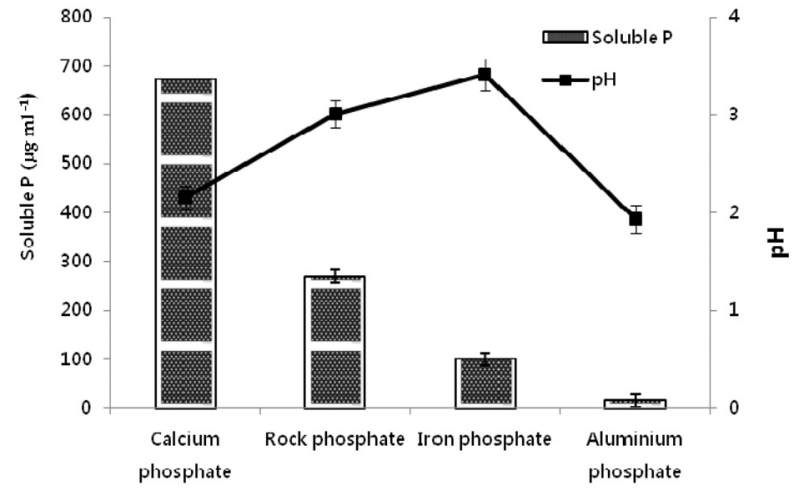

Fig. 5. Different insoluble phosphate solubilizing ability by Aspergillus awamori bxq33110. Values are mean \pm SD of three replicates.

initial stages of incubation (first 2 days) followed by slower decrease. The initial $\mathrm{pH}$ of the NBRIP medium was 7.00 and $\mathrm{pH}$ drop by phosphorus solubilizing fungal isolate to 2.15 after one week. This inverse relationship between $\mathrm{pH}$ and soluble phosphorus concentration suggested that acidification of the medium could facilitate the inorganic phosphorus solubilization.

To investigate the different insoluble phosphate sources like $\mathrm{Ca}_{3}\left(\mathrm{PO}_{4}\right)_{2}, \mathrm{AlPO}_{4}, \mathrm{FePO}_{4}$ and rock phosphate (RP) solubilizing capacity of strain Aspergillus awamori bxq33110 was assayed and results are shown in Fig. 5. As shown in Fig. 5, the strain solubilize $\mathrm{Ca}_{3}\left(\mathrm{PO}_{4}\right)_{2}$ to a greater extent followed by $\mathrm{RP}$ and $\mathrm{FePO}_{4}$. However, Aspergillus awamori bxq33110 was not effective in solubilizing $\mathrm{AlPO}_{4}$. The low solubilizing ability of $\mathrm{AlPO}_{4}, \mathrm{FePO}_{4}$ and $\mathrm{RP}$ when compared with $\mathrm{Ca}_{3}\left(\mathrm{PO}_{4}\right)_{2}$ probably due to the adaptive nature of the enzyme that is responsible for solubilizing $\mathrm{Ca}_{3}\left(\mathrm{PO}_{4}\right)_{2}$ (Banik and Dey, 1982). However, few of the other studies showed the ability of fungi to solubilize $\mathrm{Fe}$ or $\mathrm{Al}$ phosphates. Penicillum rugulosum was more efficient for solubilizing $\mathrm{AlPO}_{4}$ and $\mathrm{FePO}_{4}$ than hydroxyapatite (Reyes et al., 1999).

\section{Effect of carbon and nitrogen sources on phosphate} solubilization The phosphate solubilizing activity is determined by the microbial ability to produce and release organic acids (Chen et al., 2006). Production of organic acids was greatly affected by nature of carbon sources and the nature of organic acid is more important than the quantity of organic acid (Srividya et al., 2009). Therefore, carbon source is one of the most important factors in inorganic phosphate solubilization. As shown in Fig. 6a Aspergillus awamori bxq33110 could solubilize insoluble phosphate with all the tested carbon sources in 


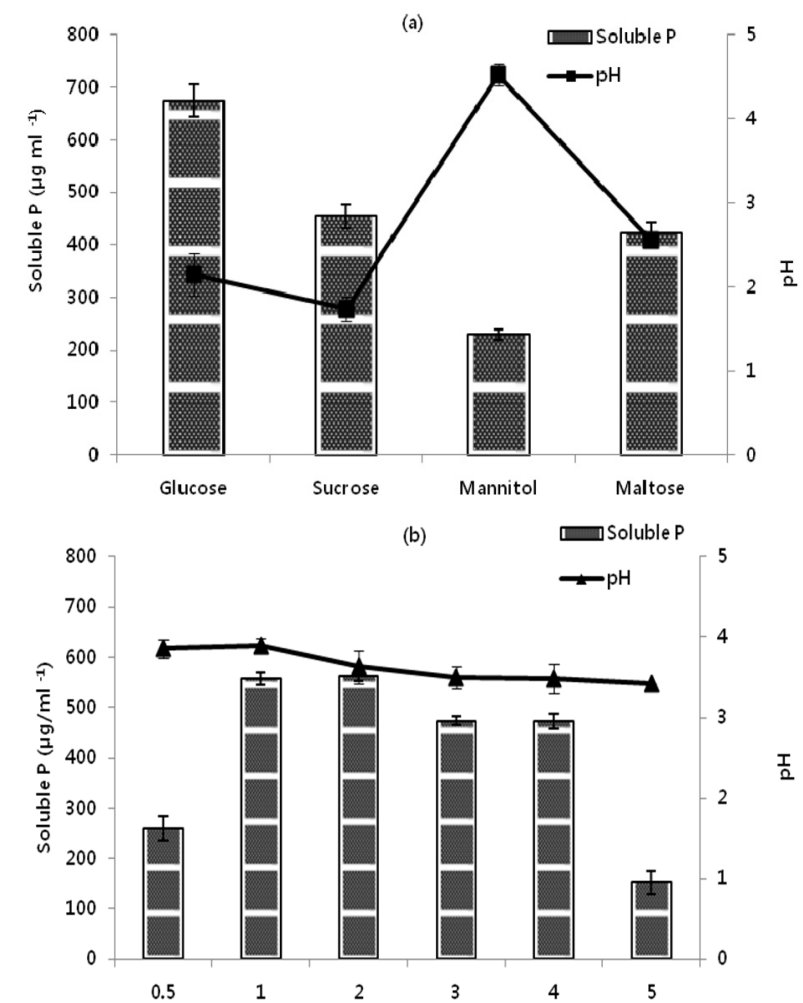

Fig 6. (a) Effect of different carbon sources on phosphate solubilization (b) Effect of different glucose concentrations on phosphate solubilization by Aspergillus awamori bxq33110. Values are mean \pm SD of three replicates.

diverse levels. Among them glucose was identified as the best carbon source and mannitol was identified as poor carbon source (672 and $212 \mu \mathrm{g} \mathrm{mL}^{-1}$ soluble P after 1 week of incubation respectively) for the insoluble phosphate solubilization by Aspergillus awamori bxq33110. In all cases, insoluble phosphate solubilization was accompanied by a distinct $\mathrm{pH}$ decrease. The highest $\mathrm{pH}$ reduction was recorded by glucose (from 7.00 to 2.15) followed by other carbon sources indicating that Aspergillus awamori bxq33110 growth did not support phosphate solubilization effectively. This shows that production of organic acid related to phosphate solubilization rather than organism growth (Hadler et al., 1991). Corresponding to this result, it has been reported that glucose is the best carbon source for phosphate solubilization in fungal strains of Aspergillus niger strain BHUAS01 (Yadav et al., 2011a), A. niger strain F7 (Srividya et al., 2009), A. tubingensis (Relwani et al., 2008) and Penicillium sp. (Saber et al., 2009).

To determine the effect of glucose concentration on the insoluble phosphate solubilization, various concentrations ranging from $0.5 \%$ to $5 \%$ were added to the medium. As

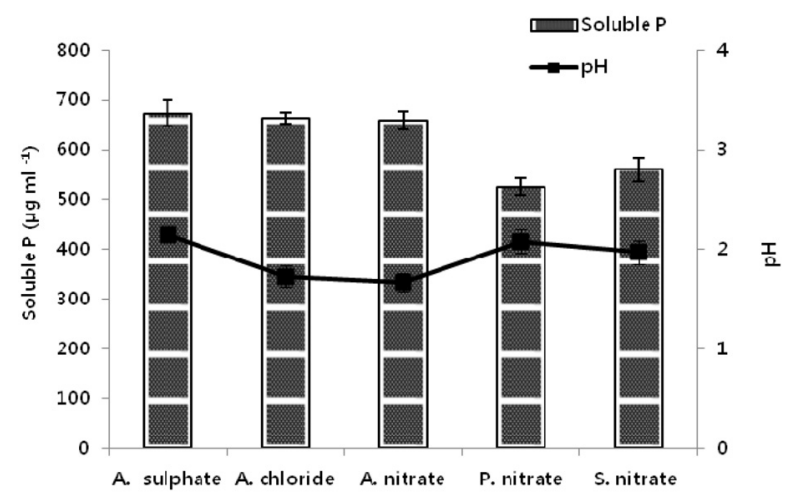

Fig. 7. Effect of different nitrogen sources on phosphate solubilization.

Values are mean \pm SD of three replicates.

depicted in Fig. 6b, phosphate solubilization was enhanced with increasing amounts of glucose up to $2 \%$, but started to decrease when it was above $2 \%$ of glucose. This finding was evident from the effect of different media on phosphate solubilization (Fig. 3). AYG medium (Halder et al., 1991) showed maximum phosphate solubilization and it happened to contain glucose concentration at $2 \%$. Nautiyal (2000) has been reported same results with Pseudomonas sp. 2 that higher phosphate solubilization at $2 \%$ glucose. However, in contrary to this finding, it has been reported that phosphate solubilization by Pantoea agglomerans R-42 was higher at 3\% glucose (Son et al., 2006).

Inorganic nitrogen sources having ammonium $\left(\mathrm{NH}_{4}{ }^{+}\right)$ or nitrate $\left(\mathrm{NO}_{3}{ }^{-}\right)$or both groups were used as nitrogen sources to assess the effect of nitrogen source on phosphate solubilization. As shown in Fig. 7, all the nitrogen sources increased the level of phosphate solubilization. Among them, $\left(\mathrm{NH}_{4}\right)_{2} \mathrm{SO}_{4}$ was the best nitrogen source followed by $\mathrm{NH}_{4} \mathrm{Cl}$ and $\mathrm{NH}_{4} \mathrm{NO}_{3}$. This is an agreement with results reported by Scervino et al. (2011) observed that highest phosphate solubilization by Penicillium purpurogenum in the presence of $\left(\mathrm{NH}_{4}\right)_{2} \mathrm{SO}_{4}$ as sole nitrogen source. This finding was also evident from the effect of different media on phosphate solubilization (Fig. 3). AYG medium (Halder et al., 1991) showed maximum phosphate solubilization having highest amount of nitrogen $(1 \%)$ as $\left(\mathrm{NH}_{4}\right)_{2} \mathrm{SO}_{4}$. This suggests that existence of $\mathrm{NH}_{4}{ }^{+} / \mathrm{H}^{+}$exchange mechanism acidifying the medium and increased the phosphate solubilization (Roos and Luckener, 1994) in the presence of $\mathrm{NH}_{4}{ }^{+}$source. It has been reported that phosphate solubilization could accelerate production of inorganic 
Table 2. Effect of high $\mathrm{pH}$, temperature and salt concentration on phosphate solubilization by Aspergillus awamori bxq33110. Values are mean \pm SD of three replicates.

\begin{tabular}{ccc}
\hline \hline & Soluble P & Final $\mathrm{pH}$ \\
\hline Initial $\mathrm{pH}$ & $\mu \mathrm{g} \mathrm{mL} \mathrm{mL}^{-1}$ & $2.15 \pm 0.08$ \\
7 & $674 \pm 11$ & $2.81 \pm 0.05$ \\
8 & $637 \pm 09$ & $3.12 \pm 0.08$ \\
9 & $620 \pm 12$ & $3.28 \pm 0.11$ \\
10 & $588 \pm 18$ & \\
Temperature $\left({ }^{\circ} \mathrm{C}\right)$ & & $2.15 \pm 0.11$ \\
30 & $674 \pm 18$ & $2.92 \pm 0.09$ \\
35 & $583 \pm 16$ & $3.78 \pm 0.06$ \\
40 & $573 \pm 15$ & \\
Salt concentration $(\%)$ & & $2.15 \pm 0.12$ \\
0 & $674 \pm 11$ & $2.51 \pm 0.15$ \\
5.5 & $685 \pm 13$ & $2.21 \pm 0.09$ \\
10 & $737 \pm 18$ & $4.18 \pm 0.07$
\end{tabular}

acids by proton exchange mechanism in the presence of ammonium ion (Ahuja et al., 2007).

\section{Effect of high pH, high salinity and high temper-} ature on phosphate solubilization The influence of high initial $\mathrm{pH}$ on the phosphate solubilization was assessed in the range of $\mathrm{pH} 7$ to 10. As depicted in Table 2, the highest phosphate solubilization was recorded at $\mathrm{pH} 7$ (674 $\mu \mathrm{g} \mathrm{mL}^{-1}$ ) and followed $\mathrm{pH} 8$ and 9 (628 and $618 \mu \mathrm{g}$ $\mathrm{mL}^{-1}$ respectively). But there was no significant difference $(\mathrm{P} \leq 0.05)$ in phosphate solubilization at $\mathrm{pH}$ 7-9. However, $\mathrm{pH}$ increased up to 10 resulted in a slight decrease in soluble phosphorus production. Fungi were naturally grown better under acidic than alkaline $\mathrm{pH}$ conditions and phosphate solubilization is associated with production of organic acids. Therefore, alkaline medium will tend to impair this process by neutralization of acidity (Yadav et al., 2011b). This result indicated that Aspergillus awamori bxq33110 is an alkali-tolerant fungi which can be applied to the alkaline soil. The strain Aspergillus awamori bxq33110 showed maximum phosphate solubilization at $30^{\circ} \mathrm{C}\left(674 \mu \mathrm{g} \mathrm{mL}{ }^{-1}\right)$. There was a slight decrease in soluble phosphorus release when temperature increased up to $40^{\circ} \mathrm{C}\left(91 \mu \mathrm{g} \mathrm{mL}^{-1}\right)$. However the results showed that the Aspergillus awamori bxq33110 could function as a phosphate solubilizer even at high temperature though slight decrease.

Effects of varying salt concentrations from 0 to $10 \%$ on phosphate solubilization and $\mathrm{pH}$ change in liquid medium are presented in Table 2. Results showed that soluble phosphorus production was maintained with increasing amounts of $\mathrm{NaCl}$ up to $5 \%$. However, the most interesting thing is that strain Aspergillus awamori bxq33110 could still produce $557 \mu \mathrm{g} \mathrm{mL}^{-1}$ soluble phosphorus at $10 \%$ of $\mathrm{NaCl}$ after 7 days of incubation. Kang et al. (2002) reported the increase phosphate solubilization in the presence of $1 \% \mathrm{NaCl}$ and Rosado et al. (1998) reported phosphate solubilization in the presence of $10 \% \mathrm{NaCl}$. However, it decreased with the increase of $\mathrm{NaCl}$ concentration. Therefore, the strain Aspergillus awamori bxq33110, can be a great benefit in maintaining phosphorus level in saline alkaline soil where as other microbes showed reduced or loss phosphate solubilizing capacity in such soils (Gyaneshwar et al., 1998).

\section{Conclusion}

Establishment and performance of phosphate solubilizing microorganisms are highly influenced by environmental factors such as $\mathrm{pH}$, temperature and salt etc, it is essential to isolate strains which can survive, multiply and spread under these conditions. This study clearly indicates that Aspergillus awamori bxq33110 is a potent alkalotolerant fungus which retains its phosphate solubilizing capacity over wide range of high $\mathrm{pH}$, high temperature and high salt concentrations. Therefore this strain can grow well in elevated $\mathrm{pH}$, temperature and salt concentrations, thus efficient for the development of microbial inoculants 
under stress conditions. However, a field based trial should be necessary to understand its behavior under field conditions.

\section{Acknowledgment}

This work was supported by Agenda grant (2012, PJ007818) from Rural Development Administration, Republic of Korea.

\section{References}

Ahuja, A., S.B. Ghosh, and S.F.D. Souza. 2007. Isolation of starch utilizing, phosphate solubilization fungus medium and its characterization. Bioresour. Technol. 98:3408-3411.

Banik, S. and B.K. Dey. 1983. Phosphate solubilizing potentiability of the microorganisms capable of utilizing aluminium phosphate as a sole phosphate source. Zentralbl Mikrbiol. 138:17-23.

Chaiharn, M. and S. Lumyong. 2009. Phosphate solubilization potential and stress tolerance of rhizobacteria from rice soil in Nothern Thailand. World J. Microbiol. Biotechnol. 25: 305-314.

Goldstein, A.H. 1986. Bacterial solubilization of mineral phosphates: historical perspectives and future prospects. Am. J. Altern. Agric. 1:51-57.

Gyaneshwar, P., K.G. Naresh, and L.J. Parekh. 1998. Effect of buffering on the phosphate solubilizing ability of microorganisms. World J. Microbiol. Biotechnol. 14:669-673.

Halder, A.K., A.K. Mishra, P. Bhatttacharya, and P.K Chakrabarty. 1991. Solubilization of inorganic phosphates by Bradyrhizobium. Indain J. Exp. Biol. 29:28-31.

Kang S.C., C.G. Ha, T.G. Lee, and D.K. Maheswari. 2002. Solubilization of insoluble inorganic phosphates by a soil-inhabiting fungus Fomitopsis sp. PS 102. Curr. Sci. 82: 439-442.

Kim, K.Y., D. Jordan, and H.B. Kirshanan. 1997. Rahnella aquatilis, a bacterium isolated from soybean rhizosphere, can solubilize hydroxyapatite. FEMS Microbiol. Lett. 153:273-277.

Lee H., H.S. Ha, C.S. Lee, Y.B. Lee, and P.J. Kim. 2006. Fly ash effect on improving soil properties and rice productivity in Korean paddy soil. Bioresour. Technol. 97: 1490-1497.

Mundra, S., R. Arora, and T. Stobdan. 2011. Solubilization of insoluble inorganic phosphates by a novel temperature, $\mathrm{pH}$, and salt tolerant yeast, Rhodotorula sp. PS4, isolated from seabuckthorn rhizosphere, growing in cold desert of Ladakh, India. World J. Microbiol. Technol. 27:2387-2396.

Murphy, J. and J. P. Riley. 1962. A modified single solution method for the determination of phosphate in mineral waters. Anal. Chim. Acta. 27:31-36.
Nautiyal, C.S. 1999 An efficient microbiological growth medium for screening of phosphate solubilizing microorganisms. FEMS Microbiol. Lett. 170: 265-270.

Nautiyal, C.S., S. Bhadauria, P. Kumar, H. Lal, R. Mondal, and D. Verma. 2000. Stress induced phosphate solubilization in bacteria isolated from alkaline soils. FEMS Microbiol. Lett. 182:291-296.

Pikovskaya, R.I. 1948. Mobilization of phosphorus in soil in connection with vital activity of some microbial species. Microbiol. 17: 362-370.

Relwani, L., P. Krishna, and M.S. Reddy. 2008. Effect of carbon and nitrogen sources on phosphate solubilization by a wild-type strain and UV-induced mutants of Aspergillus tubingensis. Curr. Microbiol. 57:401-406.

Reyes, I., L. Bernier, R.R. Simard, and H. Antoun. 1999. Effect of nitrogen source on the solubilization of different inorganic phosphates by an isolate of Penicillium rugulosum and two UV-induced mutants. FEMS microbial. Ecol. 28:281-290.

Roos, W. and K. Luckener. 1994. Relationship between proton extrusion and fluxes of ammonium ions and organic acids in Penicillium cyclopium. J. Gen. Microbiol. 130:1007-1010.

Rosado, A.S., F.S. De Azevedo, D.W. da Croz, J.D. Van Elas, and L. Seldin. 1998. Phenotypic and genetic diversity of Paeni basillus azatofeixans strains isolated from the rhizosphere soil of different grasses. J. Appl. Microbiol. 84:216-226.

Saber, W.I.A., K.M. Ghanem, and M.S. EI-Hersh. 2009. Rock phosphate solubilization by two isolates of Aspergillus niger and Penicillium sp. and their promotion to mungbean plants. Res. J. Microbiol. 4:235-250.

Scervino, J.M., V.L. Papinutti, M.S. Godoy, M.A. Rodriguez, I. D. Monica, and M. Recchi. 2011. Medium pH, carbon and nitrogen concentrations modulate the phosphate solubilization efficiency of Penicillium purpurogenum through organic acid production. J. Appl. Microbiol. 110:1215-1223.

Son, H.J., G.T. Park, M.S. Cha, and M.S. Heo. 2006. Solubilization of insoluble inorganic phosphates by a novel salt and pH tolerant Pantoea agglomerans R-42 isolated from soybean rhizosphere. Bioresour. Technol. 97: 204-210.

Srividya, S., S. Soumya, and K. Pooja. 2009. Influence of environmental factors and salinityon phosphate solubilization by a newly isolated Aspergillus niger F7 from agricultural soil. Afr. J. Biotechnol. 8:1864-1870.

Vassileva, M., N. Vassilev, and R. Azcon. 1998. Rock phosphate solubilization by Aspergillus niger on olive cake-based medium and its further application in a soil plant system. World J. Microbiol. Biotechnol. 14:281-284.

Yadav, J., J.P. Verma, K.N. Tiwari. 2011a. Solubilization of Tricalcium phosphate by fungus Aspergillus niger at different carbon source and salinity. Trends Appl. Sci. Res. 6:606-613.

Yadav, J., J.P. Verma, S.K. Yadav, and K.N. Tiwari. 2011 b. Effect of salt concentration and $\mathrm{pH}$ on soil inhabiting fungus Penicillium citrinum Thom. for soil solubilization of Tricalcium phosphate. Microbiol. J. 1:25-32. 